Canadian

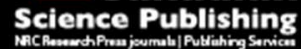

Canadian Journal of Microbiology Revue canadienne de de microbiologie

\title{
Response of Microbial Communities to Roxarsone under Different Culture Conditions
}

\begin{tabular}{|r|l|}
\hline Journal: & Canadian Journal of Microbiology \\
\hline Manuscript ID & cjm-2016-0652.R1 \\
\hline Manuscript Type: & Article \\
\hline Date Submitted by the Author: & 19 -Dec-2016 \\
\hline & $\begin{array}{r}\text { Complete List of Authors: } \\
\text { Liu, Yaci; Institute of Hydrogeology and Environmental Geology, Chinese } \\
\text { Chang; Institute of Hydrogeology and Environmental Geology, Chinese } \\
\text { Academy of Geological Sciences; CSIRO Land and Water, Urrbrae 5064 } \\
\text { South Australia, Australia } \\
\text { Fei, Yuhong; Institute of Hydrogeology and Environmental Geology, } \\
\text { Chinese Academy of Geological Sciences }\end{array}$ \\
\hline Keyword: & Roxarsone, contribution rate, diversity, Illumina MiSeq sequencing \\
\hline \multicolumn{2}{|c}{} \\
\hline
\end{tabular}

SCHOLARONE $^{\text {IM }}$

Manuscripts 


\title{
Response of Microbial Communities to Roxarsone under Different Culture
}

\section{Conditions}

\author{
Yaci Liu ${ }^{1,2}$, Zhaoji Zhang ${ }^{1}$, Yasong $\mathrm{Li}^{1,2,3 *}$, Yuhong Fei ${ }^{1}$ \\ 1 Institute of Hydrogeology and Environmental Geology, Chinese Academy of Geological Sciences, \\ Shijiazhuang, Hebei 050061, China \\ 2 Key Laboratory of Groundwater Remediation of Hebei Province and China Geological Survey, \\ Shijiazhuang, Hebei 050061, China \\ 3 CSIRO Land and Water, Urrbrae 5064 South Australia, Australia
}

\begin{abstract}
Roxarsone is a feed additive widely used in broiler and swine industry that has the potential to contaminate environment, mainly via the use of poultry manure as fertilizer, which results in release of inorganic arsenic to the soil and water. This study was conducted to investigate the roxarsone degradation and the response of microbial community under different culture conditions using high-throughput sequencing technology. Poultry litter was incubated for $288 \mathrm{~h}$ in the presence of roxarsone under light aerobic, dark aerobic, or dark anaerobic conditions, showing that roxarsone was completely degraded after $48 \mathrm{~h}$ of dark anaerobic incubation, while $79.9 \%$ and $94.5 \%$ of roxarsone was degraded after $288 \mathrm{~h}$ of dark aerobic or light aerobic incubation, respectively. Roxarsone under dark aerobic conditions with microbial inhibitor sodium azide was rarely degraded during $288 \mathrm{~h}$ of incubation, illustrating that microorganisms play an important role in roxarsone degradation. Microbial community structure was significantly different among various culture conditions. Olivibacter, Sphingobacterium and Proteiniphilum were the top three genera in the control samples. Sphingobacterium and Alishewanella dominated the light aerobic samples, while the dominant microflora of the dark aerobic samples were Acinetobacter. Pseudomonas and Advenella were the predominant genus of dark anaerobic samples. This study emphasizes the potential importance of microbes in roxarsone degradation and expands our current understanding of microbial ecology during roxarsone degradation under different environmental conditions.
\end{abstract}

Keywords Roxarsone; contribution rate; diversity; Illumina MiSeq sequencing

* Institute of Hydrogeology and Environmental Geology, Chinese Academy of Geological Sciences, 268 North Zhonghua Street, Shijiazhuang, Hebei 050061, China;

E-mail: liyasong712@126.com Tel:+8631166632369 


\section{Introduction}

Roxarsone (3-nitro-4-hydroxyphenylarsonic acid) is a non-toxic and highly water-soluble organoarsenic, which has been the first approved arsenic-containing drug extensively used in broiler poultry feed to control coccidial intestinal parasites, improve feed efficiency, and promote rapid growth (Anderson 1983; Green and Clausen 2005; Shelver 2011). Most roxarsone added to the diet is excreted almost unchanged as part of the waste, and the litter is then disposed of through land application leading to roxarsone entering into environment (Jackson et al. 2003). Its use in poultry feeds did not receive attention as an important environmental issue until roxarsone has been shown to be rapidly transformed biotically (Garbarino et al. 2003; Cortinas et al. 2000) and abiotically (Bednar et al. 2003) into more toxic derivatives such as arsenate, arsenite, dimethylarsinic acid, and 3-amino-4-hydroxyphenylarsonic acid (HAPA) (Cullen and Reimer 1989; Moody and Williams 1964; Jackson and Bertsch 2001; Brown et al. 2005). Recently, a new metabolite of roxarsone, N-acetyl-4-hydroxy-m-arsanilic acid (N-AHAA), was identified (Yang et al. 2016). These arsenical products can then contaminate soil, groundwater, and surface water (Morrison 1969; Jackson et al. 2003; Fisher et al. 2015; Chen 2007; Wang and Liao 2005; Wang et al. 2006). According to Garbarino (2003), approximately $9 \times 10^{5} \mathrm{~kg}$ of roxarsone, or $2.5 \times 10^{5} \mathrm{~kg}$ of arsenic, were discharged into the environment in the United States during 2000. Arsenic can be introduced into human food chain by plant uptake when repeated annual poultry litter with roxarsone are applied to agricultural soils, especially those used for rice cultivation (Wang et al., 2006; Williams et al., 2007). Roxarsone and some of its degradation products can also to be transported through the air to impact homes near poultry litter-applied fields, resulting in house dust arsenic levels in 29 tested homes ranging from 10.7-130 mg/kg. In China, obvious arsenic pollution in groundwater was discovered in the high-poultry-production areas of northern Shandong plain (Zhang and Fei 2012). The manufacturer of roxarsone, Pfizer subsidiary Alpharma, announced that it would discontinue the sale of roxarosne in poultry feed in the United States in 2011 . However, its use is still permitted in China, Japan, New Zealand, South Africa, and Latin America (Nachman et al. 2012). As the potential toxicity and widespread use, the transformation, transference, fate, and biological effects of roxarsone have received increased attention in recent years (Shelver 2011; Andra et al. 2010; Yao et al. 2010; Reyes et al. 2010).

Roxarsone can be degraded under aerobic or anaerobic conditions (Cortinas et al. 2006; Stolz et al. 2007; 
Mafla et al. 2015; Guzmán-Fierro et al. 2015), and the degradation process of roxarsone is greatly influenced by environmental factors such as temperature, humidity, and organic content (Sun 2012). However, the degradation rate and microbial community structure under different culture environment, such as aerobic, various lighting, and anaerobic conditions, have never been compared together.

In this study, we would: (1) evaluate the degradation rate of roxarsone under aerobic and anaerobic conditions, as well as various lighting conditions; (2) reveal the diversity and structure of microbial communities in roxarsone degradation under different culture conditions using high-throughput sequencing, and subsequently (3) preliminarily assess the potential relationships between microbial communities and roxarsone degradation under different culture conditions. The results of this study expand our current understanding of microbial ecology during roxarsone degradation under different environmental conditions, and then evaluate the effects of different poultry-litter management practices preventing and controlling roxarsone pollution.

\section{Materials and Methods}

\section{Soil Sample}

Poultry litter was obtained from a chicken farm $\left(36^{\circ} 07^{\prime} \mathrm{N} / 115^{\circ} 49^{\prime} \mathrm{E}\right)$ within Yanggu County, Northern Shandong Plain, China. The concentration of roxarsone in the diet was determined to be $34 \mathrm{mg} / \mathrm{kg}$, which is within the recommended concentration range, and 15,000 broiler chickens were reared. The poultry litter was accumulated in the open air and regularly cleaned to apply as fertilizer. The piled-up litter was collected and stored at $4{ }^{\circ} \mathrm{C}$ until further analysis. The concentration of HAPA determined in collected litter was $11.3 \mathrm{mg} / \mathrm{kg}$ and roxarsone was not detected, which might have been owing to the rapid degradation of roxarsone.

\section{Degradation Processes Experiments of Roxarsone}

The basal medium contained (per L) $0.095 \mathrm{~g}$ of $\mathrm{MgCl}_{2}, 4.2 \mathrm{~g}$ of $\mathrm{NaHCO}_{3}, 0.5 \mathrm{~g}$ of yeast extract, $10 \mathrm{mM}$ lactate (Stolz et al. 2007), and $10 \mathrm{~mL}$ each of trace elements and vitamin mix (Campbell et al. 2006). The pH was adjusted to 7.3. The slurry was prepared by suspending $5 \mathrm{~g}$ of chicken litter in $100 \mathrm{~mL}$ of sterile basal medium.

For aerobic incubation, the medium $(100 \mathrm{~mL})$ was dispensed in $250-\mathrm{mL}$ flasks with $1 \mathrm{~mL}$ litter slurry 
and $50 \mathrm{mg} / \mathrm{kg}$ roxarsone, then incubated at $37^{\circ} \mathrm{C}$ with agitation $(150 \mathrm{rpm})$ for $288 \mathrm{~h}$ under a day $/$ night cycle or in the dark. Slurry without roxarsone incubated under dark condition was used as a control. Finally, microcosms containing $0.2 \%$ sodium azide solution to inhibit microbial activity were incubated under dark condition. For anaerobic incubation, the medium $(40 \mathrm{~mL})$ was dispensed in $50-\mathrm{mL}$ headspace bottles with 1 $\mathrm{mL}$ litter slurry and $50 \mathrm{mg} / \mathrm{kg}$ roxarsone, degassed with oxygen-free $\mathrm{N}_{2}$, and sealed, then incubated at $37^{\circ} \mathrm{C}$ under dark condition. All experiments were conducted in triplicate.

Cultures were monitored daily for the disappearance of yellow color, which indicated loss of roxarsone. To evaluate roxarsone degradation, aliquots $(1 \mathrm{~mL})$ were obtained from each aerobic microcosm at $0 \mathrm{~h}, 48 \mathrm{~h}$, $96 \mathrm{~h}, 144 \mathrm{~h}, 192 \mathrm{~h}, 240 \mathrm{~h}$, and $288 \mathrm{~h}$ of incubation and from each anaerobic microcosm every $8 \mathrm{~h}$. Liquid samples were filtered through a $0.22-\mu \mathrm{m}$ millipore membrane and the filtrates was collected for roxarsone analysis.

At the end of the incubation periods, the microorganisms of the chicken litter enrichments were harvested by filtering through a $0.22-\mu \mathrm{m}$ millipore membrane. The DNA was then extracted for high-throughput sequence analysis.

\section{Amplification and Bar-coded Sequencing of Bacterial 16S rRNA Genes}

High-throughput sequencing was conducted by Majorbio Bio-pharm Technology Co., Ltd. (Shanghai, China). Genomic DNA was extracted from millipore membrane according to the manufacturer's protocol in the PowerSoil ${ }^{\circledR}$ DNA Isolation Kit (MO BIO, USA). PCR amplifications were performed in $20 \mu \mathrm{L}$ (total volume) mixtures using the ABI GeneAmp ${ }^{\circledR} 9700$ PCR cycler. The V4 and V5 hypervariable region, which was shown to be universal for nearly all bacterial taxa, was amplified using the $515 \mathrm{~F}$ (5'GTGCCAGCMGCCGCGG-3') and 907R (5'-CCGTCAATTCMTTTRAGTTT-3') primer sets with barcodes. This short targeted gene region (392 bp) can provide sufficient resolution for the accurate taxonomic classification of microbial sequences (Liu et al. 2007). PCR reactions were performed with $5 \times$ FastPfu Buffer $4 \mu \mathrm{L}$, dNTP $(2.5 \mathrm{mM}) 2 \mu \mathrm{L}$, forward primer $(5 \mu \mathrm{M}) 0.8 \mu \mathrm{L}$, reverse primer $(5 \mu \mathrm{M}) 0.8 \mu \mathrm{L}$, FastPfu Polymerase $0.4 \mu \mathrm{L}$, BSA $0.2 \mu \mathrm{L}$, template DNA $10 \mathrm{ng}$ and super purified $\mathrm{H}_{2} \mathrm{O}$, supplemented to a total reacting volume of $20 \mu \mathrm{L}$. A thermal cycle programme was performed as follows: $3 \mathrm{~min}$ of initial denaturation at $95^{\circ} \mathrm{C}$, and 27 cycles of $30 \mathrm{~s}$ at $95^{\circ} \mathrm{C}, 30 \mathrm{~s}$ at $55^{\circ} \mathrm{C}$ and $45 \mathrm{~s}$ at $72^{\circ} \mathrm{C}$ were carried out. Finally, an 
extension step of 10 min at $72^{\circ} \mathrm{C}$ was added. Each sample was conducted in triplicate. Replicate PCR reactions for each sample were pooled and purified using AxyPrepDNA Gel Extraction Kit (Axygen, USA). The recovered product was detected by $2 \%$ agarose electrophoresis and quantified using a QuantiFluor ${ }^{\mathrm{TM}_{-} \mathrm{ST}}$ blue fluorescence quantitative system (Promega, USA). A single composite sample for sequencing was prepared by combining approximately equal amounts of PCR products from each sample. The Miseq PE library was constructed and V4-V5 amplicons were sequenced using the pair-end method by Illumina Miseq.

\section{High-throughput Sequence Analysis}

Raw data generated from the high-throughput sequencing run were analyzed using the software of Mothur (Schloss et al. 2009) and QIIME (Caporaso et al. 2010). Sequence reads were trimmed and optimized by the Trimmomatic and Flash software. UCHIME was used to identify and remove chimera sequences (Edgar et al. 2011). Quality sequences were subsequently assigned to samples according to their unique 7-bp barcode. Sequence clustering was performed by Usearch with a similarity cutoff of $97 \%$, then clustered into operational taxonomic units (OTUs) and the longest sequences in each cluster were selected to be the representative sequences. The representative sequences were annotated by RDP-classifier 2.2 (QIIME), and then the community composition of each sample was conducted on the domain, phylum, class, order, family, genus, and species level.

Rarefaction analysis and alpha diversity analysis that contained Chao1, ACE, Shannon, Simpson, and Coverage were performed using the summary command of the Mothur software (http://www.mothur.org/). The relative abundance (\%) of individual taxa within each community was estimated by comparing the number of sequences assigned to a specific taxon with the number of total sequences obtained for that sample. Jackknifed unweighted pair-group method with arithmetic means (UPGMA) clustering was used to compare the microbial community similarity among the samples based on Bray-Curtis dissimilarity at the $97 \%$ similarity OTU level. Moreover, an OTU Venn diagram and heat map were drawn using the R language.

\section{Analytical Method of Roxarsone}

Roxarsone (purity $>99 \%$, CAS No.: 121-19-7, molecular formula: $\mathrm{C}_{6} \mathrm{H}_{6} \mathrm{AsNO}_{6}$, molecular weight: 263.04) was obtained from Dr. Ehrenstorfer (Augsburg, Germany). A high-performance liquid chromatograph (LC-20AD; Shimadzu Corporation, Japan) with a diode array detector (SPD-M20A) was 
used to measure roxarsone. The chromatograph was equipped with a Shimpak-ODS C18 column (250 mm $\times 4.6 \mathrm{~mm}, 5 \mu \mathrm{m}$, Shimadzu Corporation, Japan). The mobile phase was composed of $0.02 \mathrm{~mol} / \mathrm{L} \mathrm{KH}_{2} \mathrm{PO}_{4}$, methanol and 10\% (V/V) formic acid (60:20:20, V/V/V) at a flow rate of $1.0 \mathrm{~mL} / \mathrm{min}$. The column temperature was maintained at $30^{\circ} \mathrm{C}$.

\section{Results and Discussion}

\section{Degradation Processes of Roxarsone under Different Environmental Conditions}

Roxarsone concentration under different environmental conditions over time are shown in Figure 1. For further quantitative analysis, residual quantity and degradation rate along with incubation time (every $48 \mathrm{~h}$ for aerobic conditions and $8 \mathrm{~h}$ for anaerobic condition) are shown in Table 1. As the table shows, in different treatments, the degradation rates at early stage of cultivation increased faster than late stage of cultivation. After $144 \mathrm{~h}$ of incubation, the degradation rates under dark aerobic or light aerobic conditions were $40 \%$ and $66.2 \%$, respectively, and the degradation rate under dark anaerobic incubation was $76.3 \%$ after $24 \mathrm{~h}$ of incubation. Roxarsone was completely degraded after $48 \mathrm{~h}$ of dark anaerobic incubation, which was significantly faster than other environment conditions. The degradation rates under dark aerobic or light aerobic conditions were $79.9 \%$ and $94.5 \%$, respectively, after $288 \mathrm{~h}$ of incubation, illustrating that the contribution of photolysis to roxarsone degradation was about $14.6 \%$. Roxarsone under dark aerobic conditions with $0.2 \%$ sodium azide was rarely degraded during $288 \mathrm{~h}$ of incubation, while $79.9 \%$ of the added roxarsone was degraded under dark aerobic conditions, showing that microorganisms play an essential role in roxarsone degradation and the contribution of microbial action to roxarsone degradation was about $79.9 \%$.

Difference of the concentration changes under different culture conditions were compared with one-way analysis of variance using SPSS, showing that there was no significant difference between dark aerobic condition and light aerobic condition $(\mathrm{P}>0.05)$, sterile dark aerobic condition showed significant difference with all other three culture conditions $(\mathrm{P}<0.05)$, and dark anaerobic condition showed significant difference with all other three culture conditions $(\mathrm{P}<0.05)$. From the results of significance test of difference, it could be found that the effects of photolysis contributed little to roxarsone degradation and the effects of microbial action and anaerobic condition were more significant on roxarsone degradation. The contribution rate of microbial action was much larger than that of photolysis, which was similar to that reported by 
Garbarino (2003), who found that the effects of photodegradation were most likely insignificant relative to microbial action. Furthermore, among different environmental conditions, roxarsone degraded fastest under anaerobic conditions, indicating that roxarsone degradation was inclined to happen under anaerobic condition, which was similar to that reported in a study by Stolz (2007). The organic-rich manure and anaerobic conditions provide the conditions necessary for the native microbial populations to transform roxarsone in the litter and release more toxic inorganic arsenic. Therefore, different poultry-litter management practices should lead to different roxarsone degradation rates, which can enable more scientific and reasonable treatment of poultry litter with roxarsone.

The effects of sodium azide as a broad-spectrum microbial inhibitor were examined to determine if biotic processes were controlling roxarsone degradation. Tests showed that sodium azide alone had no chemical reactivity with roxarsone or any other arsenic species in reagent water. In the study of Garbarino (2003), the addition of $0.25 \%$ sodium azide to the litter compost did not inhibit the degradation indefinitely, roxarsone was degraded to concentrations below detection limit after $35 \mathrm{~d}$, which was $14 \mathrm{~d}$ longer than the experiments that did not have azide. While in this experiment, the addition of sodium azide to the litter solution inhibited the degradation definitely.

\section{Sequencing and Classification}

High-throughput sequencing analysis not only provides quantitative insight into the effects of roxarsone on major microbial groups, but is also capable of generating high throughput and reproducibility during monitoring of microbial communities. This study attempted to assess the response of microbial communities to roxarsone under different environmental culture using a high-throughput sequencing approach.

After quality control, a total of 101,671 high-quality, non-plastid, and partial sequences were queried. The number of sequences retained per sample varied from 24,544 to 26,651 , with an average sequence length of $394 \mathrm{bp}$. The total number of different OTUs in the four samples was 300. Richness and diversity indices of microbial community from different culture conditions are shown in Table 2 . The calculated coverage value (Table 2) combined with the rarefaction curves (not shown) suggested that these libraries detected a majority of the bacterial diversity in the samples used in our study. The diversity indices (Table 2) showed that the microbial diversity of control samples without roxarsone (CK) were significantly higher than those of the 
other three samples with roxarsone, implying that some bacteria tended to be restrained by roxarsone. Among the three samples with roxarsone, the microbial diversity of the dark aerobic sample (DA) was higher and the microbial diversity of the dark anaerobic sample (DAN) was the lowest. The Venn diagram (Figure 2) shows the unique OTU numbers for every sample and the shared OTU numbers among the four samples. Overall, 52 OTUs were common to all four samples.

Some studies have been conducted on the effect of roxarsone on microbes. Roxarsone has been shown to have a significantly detrimental effect on indigenous microbial community diversity and metabolic activity in soil (Jiang et al. 2013). However, roxarsone does not exert acute toxicity on soil microbes by analyzing the fluorescein diacetate (FDA) hydrolysis activity and FDA hydrolysis activity was inhibited gradually with the release of inorganic arsenic (Liang et al. 2014). As(V) and As(III)-bearing photodegradates of roxarsone exhibited 10 times more toxicity compared with original roxarsone with regards to the IC50 and EC50 values. The enhanced toxicity was attributed to the improved membrane permeability of the inorganic arsenicals in the photodegradates of roxarsone (Zhang et al. 2015). In the study of Mafla (2015), it was also confirmed that untransformed roxarsone was not a toxic product for eukaryotic or prokaryotic cells, and the toxicity was caused by the consequence of roxarsone biodegradation. Therefore, in this study, the inhibition of some soil bacteria might not occur as a result of roxarsone but rather from the arsenic compounds released by roxarsone degradation.

\section{Microbial Community Abundance and Diversity of Different Treatments at the Phylum Level}

Microbial community compositions and relative abundances of bacterial taxa recovered from different treatments are shown in Figure 3, with Figure 3A and 3B showing the relative abundance of phyla and genera, respectively. Figure 4 shows the detected bacterial taxa summarized as a heat map, with Figure 4A and 4B showing bacteria-phylum level distribution and bacteria-genus level distribution, respectively.

Detailed phylogenetic analyses grouped the bacterial sequences into 7 phyla (Figure 3A) and 34 genera (Figure 3B). As shown in Figure 3A and Figure 4A, the dominant microflora were Proteobacteria, Bacteroidetes, and Firmicutes in the four samples; however, the relative abundance of these dominant phyla in each sample and the diversity of different treatments differed significantly. The relative abundance of the bacterial community was compared in different treatments. The abundance of Proteobacteria in untreated 
manure without roxarsone (CK), dark aerobic cultivation (DA), light aerobic cultivation (LA), and dark anaerobic cultivation (DAN) was $27.2 \%, 38.8 \%, 59.5 \%$, and $78.7 \%$, respectively, showing that the abundance of Proteobacteria in the control sample was lower than that in the other three treated samples, and the abundance of Proteobacteria under anaerobic cultivation was highest. The abundance of Bacteroidetes in samples CK, DA, LA, and DAN was $50.2 \%, 41.4 \%, 30.3 \%$, and $9.2 \%$, respectively. The abundance of Firmicutes in samples CK, DA, LA, and DAN was $18.8 \%, 10.1 \%, 2.7 \%$, and $11.9 \%$, respectively. The abundance of Bacteroidetes and Firmicutes in the three samples treated with roxarsone was lower than that in the control sample. The diversity of anaerobic cultivation was lowest among the four samples.

The abundance of Proteobacteria in samples with roxarsone was significantly higher than in the control sample, which was likely because roxarsone can stimulate the growth of some bacterial groups. Moreover, when compared with the degradation rate of roxarsone, a higher abundance of Proteobacteria was associated with a higher degradation rate. For instance, the abundance of Proteobacteria during anaerobic cultivation was highest, as was the degradation rate, inferring that Proteobacteria was likely related to roxarsone degradation, together with an arsenic resistance system (ars) has been found in Proteobacteria and has been described for bacteria such as Escherichia coli (Carlin et al. 1995; Diorio et al. 1995), Pseudomonas aeruginosa (Cai et al. 1998), Acidiphilum multivorum (Suzuki et al.1998), and Acidithiobacillus caldus (Dopson et al. 2001).

Other dominant microflora were Bacteroidetes and Firmicutes in the four samples, similarly, in the study of Guzmán-Fierro (2015), Firmicutes were the most predominant group in the consortium of roxarsone. Firmicutes have been shown to be the predominant microorganisms in soils, sediments and animal faeces. In addition, roxarsone can be biotransformed into inorganic arsenical compounds by Clostridium spp., which belong to Firmicutes and have been isolated from chicken faeces (Stolz et al. 2007). Decreased Bacteroidetes and Firmicutes abundance was also observed in the roxarsone treatment samples, showing that these bacteria tended to be more sensitive to roxarsone. The abundance of Bacteroidetes became lower as the roxarsone degradation rate increased, which was contrary to the variations in Proteobacteria abundance. The diversity and abundance of bacteria in different treatments were significantly different at the genus level. Specifically, there were significant differences in dominant bacteria among different treatments, which could lead to a preliminary identification of critical genera under different environmental conditions. 


\section{Microbial Community Abundance and Diversity of Different Treatments at the Genus Level}

As shown in Figure 3B and Figure 4B, the microbial community structures of the four samples were significantly different at the genus level. The microbial evenness of the control sample was better and the dominant microflora were Olivibacter (12.7\%), Sphingobacterium (8.2\%), and Proteiniphilum (8.0\%), of which Olivibacter and Proteiniphilum existed almost solely in the control sample, indicating that these two genera might be constrained by roxarsone. The dominant microflora of the light aerobic samples were Sphingobacterium (20.2\%) and Alishewanella (21.9\%). Additionally, the abundances of these two genera were obviously higher than those of other samples, especially Alishewanella. The dominant microflora of the dark aerobic sample was Acinetobacter (19.3\%), which was present in the highest abundance among the four samples. In addition, Fluviicola, Sphingobacteriaceae_Unclassified, and Planctomyces existed almost solely in the dark aerobic sample. The microbial diversity of the anaerobic sample was poorest among the four samples and Pseudomonas (28.8\%) and Advenella (37.8\%) were the top two genera, which were present at relative abundances of more than $60 \%$ and levels distinctly higher than in the other samples. Moreover, Advenella existed almost solely in the anaerobic sample, indicating that this genus more likely grew under anaerobic conditions, but its relation with roxarsone degradation wasn't discussed before, whose role in roxarsone degradation needed a further study. Likewise, Alishewanella, Acinetobacter and Pseudomonas had been identified to be capable of reduction and discovered to be predominant groups in high arsenic groundwater (Li et al. 2015; Fan et al. 2008). Furthermore, Alishewanella sp. strain GIDC-5, Acinetobacter sp. strain GW7, Pseudomonas mendocina strain GW9, Pseudomonas aeruginosa, Pseudomonas arsenicoxydans and Pseudomonas putida strain WB have been found to be involved in As cycling including arsenic resistance, arsenic reduction and oxidation (Fan et al. 2008; Shaha et al. 2013; Freikowski et al. 2010; Campos et al. 2010).

In summary, the degradation processes of roxarsone under different environmental conditions were evaluated, showing that the contribution rate of microbial action was largest for roxarsone degradation, and roxarsone was more likely to be degraded under anaerobic condition, which would evaluate the effect of different poultry-litter management practices. Additionally, Illumina MiSeq sequencing was used to illustrate that the microbial community were distinctly different under different culture conditions and the application of roxarsone might positively changed microbial community structures, contributing to revealing the relation 
between microbial community and roxarsone degradation under different culture conditions.

\section{Acknowledgments}

This work was supported by grants from the National Natural Science Foundation of China awarded in 2014 (No. 41402235). The authors gratefully acknowledge Sheng Zhang and Cuiyun Zhang of Institute of Hydrogeology and Environmental Geology, CAGS for fruitful discussions and comments. The authors thank edanz (https://www.edanzediting.com/) for linguistic assistance during the preparation of this manuscript.

\section{References}

Anderson, C. 1983. Arsenicals as feed additives for poultry and swine. Arsenic: industrial, biomedical, environmental perspectives. Van Nostrand Reinhold, New York.

Andra, S.S., Makris, K.C., Quazi, S., Sarkar, D., Datta, R., and Bach, S.B. 2010. Organocopper complexes during roxarsone degradation in wastewater lagoons. Environ Sci Pollut R 17(5):1167-1173.

Bednar, A.J., Garbarino, J.R., Ferrer, I., Rutherford, D.W., and Wershaw, R.L. 2003. Photodegradation of roxarsone in poultry litter leachates. Sci Total Environ 302:237-245.

Brown, B.L., Slaughter, A.D., and Schreiber, M.E. 2005. Controls on roxarsone transport in agricultural watersheds. Appl Geochem 20:123-133.

Carlin, A., Shi, W., Dey, S., and Rosen, B.P. 1995. The ars operon of Escherichia coli confers arsenical and antimonial resistance. J Bacteriol 177:981-986

Cai, J., Salmon, K., and DuBow, M.A. 1998. Chromosomal ars operon homologue of Pseudomonas aeruginosa confers increased resistance to arsenic and antimony in Escherichia coli. Microbiology $144: 2705-2713$

Campbell, K.M., Davin, M., Saltikov, C.W., Newman, D.K., and Hering, J.G. 2006. Simultaneous microbial reduction of iron(III) and arsenic(V) in suspensions of hydrous ferric oxide. Environ Sci Technol 40:5950-5955.

Campos, V.L., Valenzuela, C., Yarza, P., Kämpfer, P., Vidal, R., and Zaror, C. 2010. Pseudomonas arsenicoxydans, sp nov. an arsenite-oxidizing strain isolated from the Atacama desert. Systematic \& Applied Microbiology 33(4):193-197 
Caporaso, J.G., Kuczynski, J., Stombaugh, J., Bittinger, K., Bushman, F.D., Costello, E.K., Fierer, N., Pena, A.G., Goodrich, J.K., and Gordon, J.I. 2010. QIIME allows analysis of high-throughput community sequencing data. Nat Methods 7:335-336.

Chen, D. 2007. The soil ecological toxicity of roxarsone. Dissertation, Yangzhou University.

Cortinas, I., Field, J.A., Kopplin, M., Garbarino, J.R., Jay A.G., and Reyes, S.A. 2006. Anaerobic biotransformation of roxarsone and related n-substituted phenylarsonic acids. Environ Sci Technol 40(9):2951-2957.

Cullen, W.R., and Reimer, K.J. 1989. Arsenic speciation in the environment. Chemical Reviews 89: 713-764.

Diorio, C., Cai, J., Marmor, J., Shinder, R., and DuBow, M. 1995. An Escherichia coli chromosomal ars operon homolog is functional in arsenic detoxification and is conserved in gram-negative bacteria. $\mathrm{J}$ Bacteriol 177:2050-2056

Dopson, M., Lindstrom, E., and Hallberg, K. 2001. Chromosomally encoded arsenical resistance of the moderately Thermophilic acidophile Acidithiobacillus caldus. Extremophiles 5:247-255

Edgar, R.C., Haas, B.J., Clemente, J.C., Quince, C., and Knight, R. 2011. UCHIME improves sensitivity and speed of chimera detection. Bioinformatics 27:2194-2200.

Fan, H., Su, C., Wang, Y., Yao, J., Zhao, K., Wang, Y., and Wang, G. 2008. Sedimentary arsenite-oxidizing and arsenate-reducing bacteria associated with high arsenic groundwater from Shanyin, Northwestern China. J Appl Microbiol 105: 529 - 539.

Freikowski, D., Winter, J., and Gallert, C. 2010. Hydrogen formation by an arsenate-reducing Pseudomonas putida, isolated from arsenic-contaminated groundwater in West Bengal, India. Appl Microbiol Biotechnol 88: 1363-1371.

Fisher, D.J., Yonkos, L.T., and Staver, K.W. 2015. Environmental concerns of roxarsone in broiler poultry feed and litter in Maryland, USA. Environ Sci Technol 49(4):1999-2012.

Garbarino, J.R., Bednar, A.J., Rutherford, D.W., Beyer, R.S., and Wershaw, R.L. 2003. Environmental Fate of Roxarsone in Poultry Litter. I. Degradation of Roxarsone during Composting. Environ Sci Technol $37: 1509-1514$ 
Green, F., and Clausen, C.A. 2005. Copper tolerance of brown-rot fungi: oxalic acid production in southern pine treated with arsenic-free preservatives. Int Biodeter Biodegr 56:75-79.

Guzmán-Fierro, V.G., Moraga, R., León, C.G., Campos, V.L., Smith, C., and Mondaca, M.A. 2015. Isolation and characterization of an aerobic bacterial consortium able to degrade roxarsone. Int J Environ Sci Te 12: $1353-1362$.

Jackson, B.P., and Bertsch, P.M. 2001. Determination of arsenic speciation in poultry wastes by IC-ICP-MS. Environ Sci Technol 35:4868-4873.

Jackson, B.P., Bertsch, P.M., Cabrera, M.L., Camberato, J.J., Seaman, J.C., and Wood, C.W. 2003. Trace element speciation in poultry litter. J Environ Qual 32:535-540.

Jiang, Z., Li, P., Wang, Y., Li, B., and Wang, Y. 2013. Effects of roxarsone on the functional diversity of soil microbial community. Int Biodeter Biodegr 76:32-35.

Li, P., Wang, Y., Dai, X., Zhang, R., Jiang, Z., Jiang, D.W., Wang, S., Jiang, H.C., Wang, Y.X., and Dong, H.L. 2015. Microbial Community in High Arsenic Shallow Groundwater Aquifers in Hetao Basin of Inner Mongolia, China. PLoS ONE 10(5): e0125844. doi: 10.1371/journal.pone.0125844

Liang, T.F., Ke, Z.C., Chen, Q., Liu, L., and Chen, G.W. 2014. Degradation of roxarsone in a silt loam soil and its toxicity assessment. Chemosphere 112: 128-33.

Liu, Z., Lozupone, C., Hamady, M., Bushman, F.D., and Knight, R. 2007. Short pyrosequencing reads suffice for accurate microbial community analysis. Nucleic Acids Res 35(18):e120.

Mafla, S., Moraga, R., León, C.G., Guzmán-Fierro, V.G., Yañez, J., Smith, C.T., Mondaca, M.A., and Campos, V.L. 2015. Biodegradation of roxarsone by a bacterial community of underground water and its toxic impact. World J Microb Biot 31:1267-1277.

Moody, J.P., and Williams, R.T. 1964. The metabolism of 4-hydroxy-3-nitrophenylarsonic acid in hens. Food and Cosmetics Toxicology 2:707-715.

Morrison, J.L. 1969. Distribution of arsenic from poultry litter in broiler chickens, soil, and crops. J Agr Food Chem 17:1288-1290.

Nachman, K.E., Graham, J.P., Price, L.B., and Silbergeld, E.K. 2005. Arsenic: a roadblock to potential animal waste management solutions. Environ Health Persp 113:1123-1124. 
Nachman, K., Raber, G., Francesconi, K., Navas-Acien, A., and Love, D. 2012. Arsenic species in poultry feather meal. Sci Total Environ 417:183-188.

O'connor, R., O'connor, M., Irgolic, K., Sabrsula, J., Gürleyük, H., Brunette, R., Howard, C., Garcia, J., Brien, J., and Brien, J. 2005. Transformations, air transport, and human impact of arsenic from poultry litter. Environ Forensics 6:83-89.

Shelver, W.L. 2011. Generation of antibody and development of an enzyme-linked immunosorbant assay for the feed additive roxarsone. Food Agr Immunol 22:171-184.

Schloss, P.D., Westcott, S.L., Ryabin, T., Hall, J.R., Hartmann, M., Hollister, E.B., Lesniewski, R.A., Oakley, B.B., Parks, D.H., and Robinson, C.J. 2009. Introducing mothur: open-source, platform-independent, community-supported software for describing and comparing microbial communities. Appl Microbiol

Shaha, R., and Jha, S. 2013. Alishewanella sp. strain GIDC-5, Arsenite hyper-tolerant bacteria isolated from industrial effluent of South Gujarat, India. Chem Ecol 29: 427-436.

Sierra-Alvarez, R., Cortinas, I., and Field, J.A. 2010. Methanogenic inhibition by roxarsone (4-hydroxy-3-nitrophenylarsonic acid) and related aromatic arsenic compounds. J Hazard Mater $175(1-3): 352-358$.

Stolz, J.F., Perera, E., Kilonzo, B., Kail, B., Crable, B., Fisher, E., Ranganathan, M., Wormer, L., and Basu, P. 2007. Biotransformation of 3-nitro-4-hydroxybenzene arsonic acid (roxarsone) and release of inorganic arsenic by clostridium species. Environ Sci Technol 41(3):818-823.

Sun, J. 2012. Chemical behaviour and biological response of roxarsone in the soil. Dissertation, Shenyang Agriculture University.

Suzuki, K., Wakao, N., Kimura, T., Sakka, K., and Ohmiya, K. 1998. Expression and regulation of the arsenic resistance operon of Acidiphilum multivorum AIU 301 plasmid pKW301 in Escherichia coli. Appl Environ Microbiol 64:411-418

Wang, F., Chen, Z., Sun, Y., Gao, Y., and Yu, J. 2006. Investigation on the pollution of organoarsenical additives to animal feed in the surroundings and farmland near hog farms. Acta Ecologica Sinica 26(1):154-162.

https://mc06.manuscriptcentral.com/cjm-pubs 
Wang, F., Chen, Z., Zhang, L., Gao, Y., and Sun, Y. 2006. Arsenic uptake and accumulation in rice (Oryza sativa L.) at different growth stages following soil incorporation of roxarsone and arsanilic acid. Plant Soil 285:359-367.

Wang, K., and Liao, X. 2005. Study on the distribution and migrating disciplinavian of arsenic around the pig farm. Journal of Domestic Animal Ecology 26(2):29-32.

Williams, P.N., Raab, A., Feldmann, J., and Meharg, A.A. 2007. Market basket survey shows elevated levels of As in south central U.S. processed rice compared to California: Consequences for human dietary exposure. Environ. Sci. Technol. 41(7):2178-2183.

Yang, Z., Peng, H., Lu, X., Liu, Q., Huang, R., Hu, B., Kachanoski, G., Zuidhof, M.J., and Le, X.C. 2016. Arsenic metabolites, including N-Acetyl-4-hydroxy-m-arsanilic acid, in chicken litter from a roxarsone-reeding study involving 1600 chickens[J]. Environ. Sci. Technol. 50(13):6737_6743.

Yao, L., Li, G., Zhi, D., Yang, B., He, Z., and Zhou, C. 2010. Uptake and transport of roxarsone and its metabolites in water spinach as affected by phosphate supply. Environmental Toxicology \& Chemistry 29:947-951.

Zhang, W., Xu, F., Han, J., Sun, Q., and Yang, K. 2015. Comparative cytotoxicity and accumulation of roxarsone and its photodegradates in freshwater Protozoan Tetrahymena thermophila. J Hazard Mater $286: 171-178$

Zhang, Z., Fei, Y., Guo, C., Qian, Y., and Li, Y. 2012. Regional groundwater contamination assessment in the North China Plain. Jornal of Jilin University (Earth Scienca Edition) 42(5):1456-1461. 
Table 1 Residual quantity and degradation rate along with incubation time

\begin{tabular}{|c|c|c|c|c|c|c|c|c|c|}
\hline & \multicolumn{2}{|c|}{$\mathrm{DA}^{*}$} & \multicolumn{2}{|c|}{$\mathrm{LA}^{*}$} & \multicolumn{2}{|c|}{ Sterile-DA ${ }^{*}$} & \multicolumn{3}{|c|}{ DAN $^{*}$} \\
\hline Time (h) & $\begin{array}{l}\text { Residual quantity } \\
\text { (mg/kg) }\end{array}$ & $\begin{array}{c}\text { Degradation rate } \\
(\%)\end{array}$ & $\begin{array}{l}\text { Residual quantity } \\
(\mathrm{mg} / \mathrm{kg})\end{array}$ & $\begin{array}{c}\text { Degradation rate } \\
(\%)\end{array}$ & $\begin{array}{l}\text { Residual quantity } \\
(\mathrm{mg} / \mathrm{kg})\end{array}$ & $\begin{array}{c}\text { Degradation rate } \\
(\%)\end{array}$ & Time (h) & $\begin{array}{l}\text { Residual quantity } \\
(\mathrm{mg} / \mathrm{kg})\end{array}$ & $\begin{array}{c}\text { Degradation rate } \\
(\%)\end{array}$ \\
\hline 0 & 50.0 & 0 & 50.0 & 0 & 50.0 & 0 & 0 & 50.0 & 0 \\
\hline 48 & 46.0 & 8.0 & 46.0 & 8.0 & 50.1 & 0 & 8 & 13.8 & 72.4 \\
\hline 96 & 40.2 & 19.6 & 43.0 & 14.0 & 50.5 & 0 & 16 & 12.7 & 74.7 \\
\hline 144 & 30.0 & 40.0 & 16.9 & 66.2 & 49.8 & 0.4 & 24 & 11.9 & 76.3 \\
\hline 192 & 15.2 & 69.6 & 7.8 & 84.4 & 49.2 & 1.6 & 32 & 4.8 & 90.3 \\
\hline 240 & 13.4 & 73.2 & 6.0 & 88.0 & 49.5 & 1.0 & 40 & 0.3 & 99.4 \\
\hline 288 & 10.1 & 79.9 & 2.8 & 94.5 & 49.4 & 1.2 & 48 & 0.0 & 100 \\
\hline & & & & & & & 56 & 0.0 & 100 \\
\hline
\end{tabular}

* DA represents dark aerobic condition, LA represents light aerobic condition, Sterile-DA represents dark aerobic condition with $0.2 \%$ sodium azide, and DAN

represents dark anaerobic condition. 
Table 2 Richness and diversity indices of microbial community from different culture conditions

\begin{tabular}{|c|c|c|c|c|c|c|c|}
\hline \multirow[b]{2}{*}{ Sample ID } & \multirow[b]{2}{*}{ Reads } & \multicolumn{6}{|c|}{0.97} \\
\hline & & OTU & $\mathrm{ACE}$ & Chao & $\begin{array}{c}\text { Coverage } \\
(\%)\end{array}$ & $\begin{array}{l}\text { Shannon's } \\
\text { Index }\end{array}$ & Simpson's Index \\
\hline $\mathrm{DA}^{*}$ & 16,584 & 195 & $\begin{array}{c}218 \\
(206,243)\end{array}$ & $\begin{array}{c}231 \\
(210,285)\end{array}$ & 99.8 & $\begin{array}{c}3.64 \\
(3.61,3.66)\end{array}$ & $\begin{array}{c}0.062 \\
(0.06,0.064)\end{array}$ \\
\hline $\mathrm{LA}^{*}$ & 19,031 & 175 & $\begin{array}{c}199 \\
(187,223)\end{array}$ & $\begin{array}{c}208 \\
(189,254)\end{array}$ & 99.8 & $\begin{array}{c}3.03 \\
(3.01,3.05)\end{array}$ & $\begin{array}{c}0.1071 \\
(0.1046,0.1096)\end{array}$ \\
\hline $\mathrm{CK}^{*}$ & 19,238 & 174 & $\begin{array}{c}186 \\
(179,203)\end{array}$ & $\begin{array}{c}198 \\
(182,245)\end{array}$ & 99.9 & $\begin{array}{c}3.79 \\
(3.78,3.81)\end{array}$ & $\begin{array}{c}0.0411 \\
(0.04,0.0421)\end{array}$ \\
\hline $\mathrm{DAN}^{*}$ & 22,223 & 138 & $\begin{array}{c}155 \\
(146,176)\end{array}$ & $\begin{array}{c}151 \\
(143,174)\end{array}$ & 99.9 & $\begin{array}{c}2.16 \\
(2.13,2.18)\end{array}$ & $\begin{array}{c}0.2325 \\
(0.2285,0.2364)\end{array}$ \\
\hline
\end{tabular}

* DA represents dark aerobic condition, LA represents light aerobic condition, CK represents the control sample without roxarsone under dark condition, and DAN represents dark anaerobic condition. 


\section{Figure Captions}

Figure 1 Roxarsone degradation under different environmental conditions. Figure 1A shows roxarsone degradation under dark aerobic conditions (solid line with square), light aerobic conditions (solid line with circle), dark aerobic conditions with $0.2 \%$ sodium azide (solid line with triangle), and Figure 1B shows roxarsone degradation under dark anaerobic conditions (solid line with rhombus)

Figure 2 Venn diagram showing shared OTUs among the four samples

Figure 3 Relative abundances of bacterial taxa recovered from each sample with cluster tree. Figure $3 \mathrm{~A}$ shows the relative abundance of phyla. Figure 3B shows the relative abundance of genera

Figure 4 Heat map of bacterial taxa. A more red color indicates higher relative abundance. Figure 4A shows the bacteria-phylum level distribution and Figure 4B shows bacteria-genus level distribution 

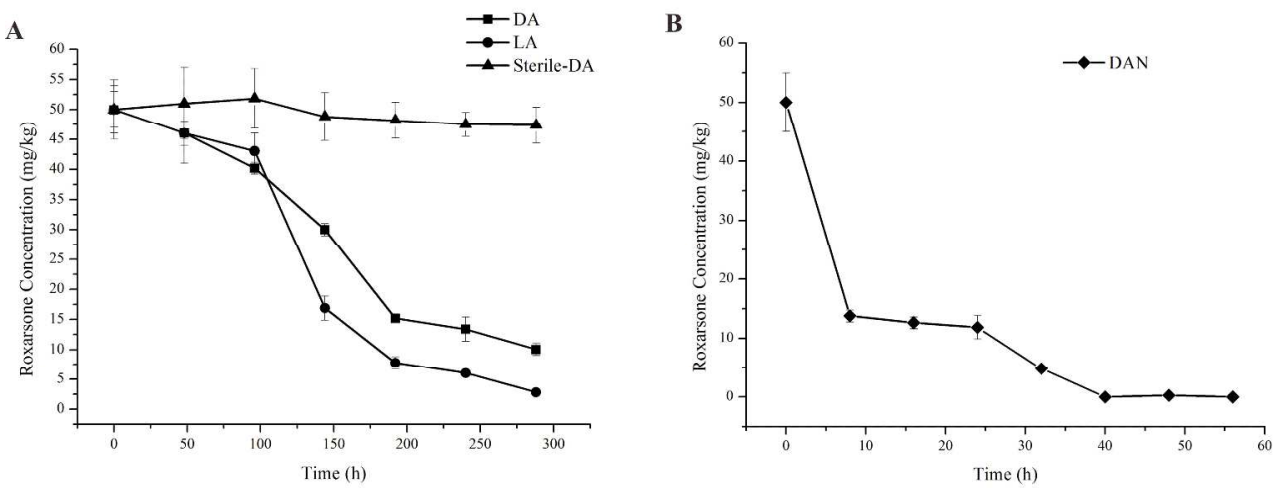

Figure 1 Roxarsone degradation under different environmental conditions. Figure 1A shows roxarsone degradation under dark aerobic conditions (solid line with square), light aerobic conditions (solid line with circle), dark aerobic conditions with $0.2 \%$ sodium azide (solid line with triangle), and Figure $1 \mathrm{~B}$ shows roxarsone degradation under dark anaerobic conditions (solid line with rhombus) 


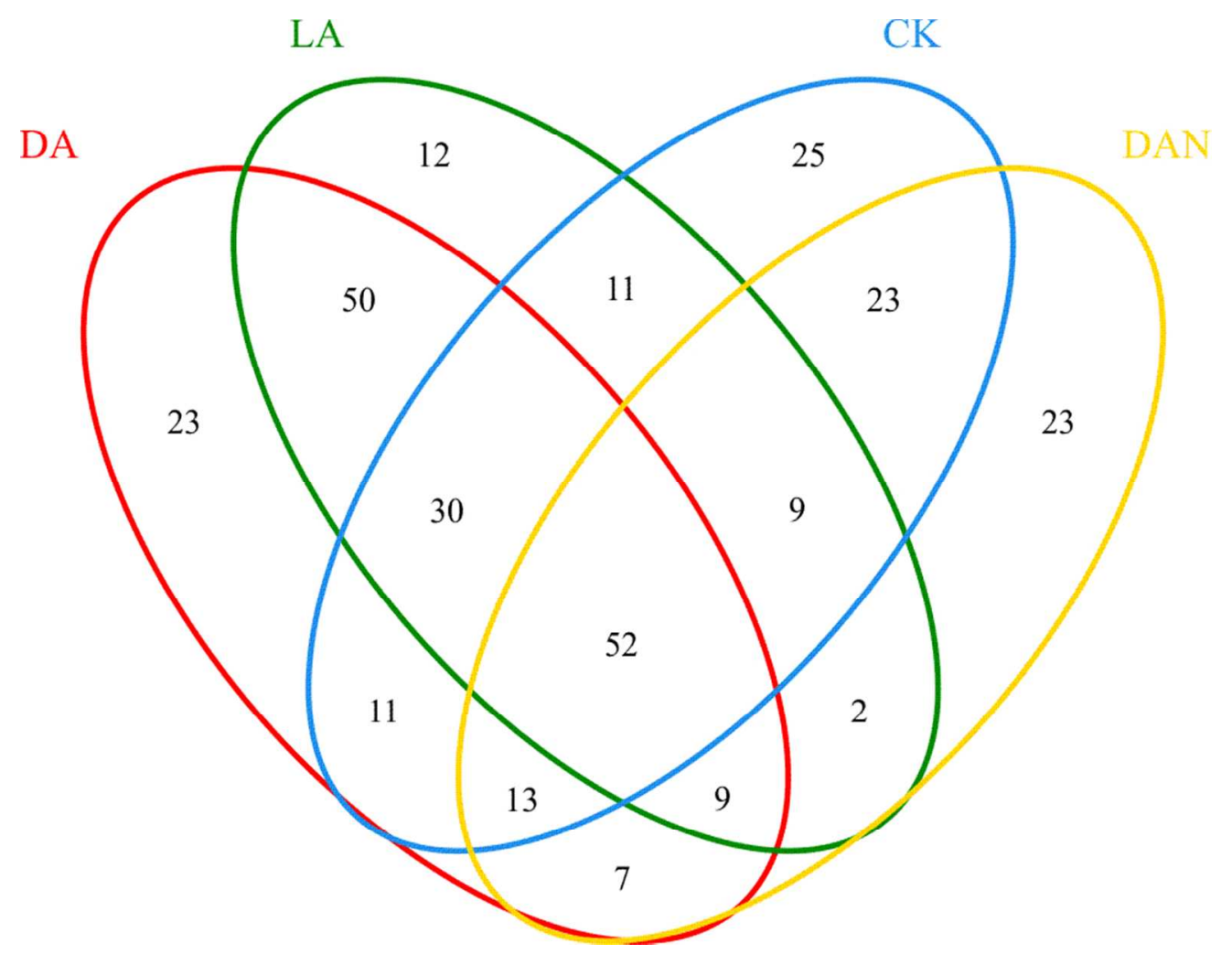

Figure 2 Venn diagram showing shared OTUs among the four samples 

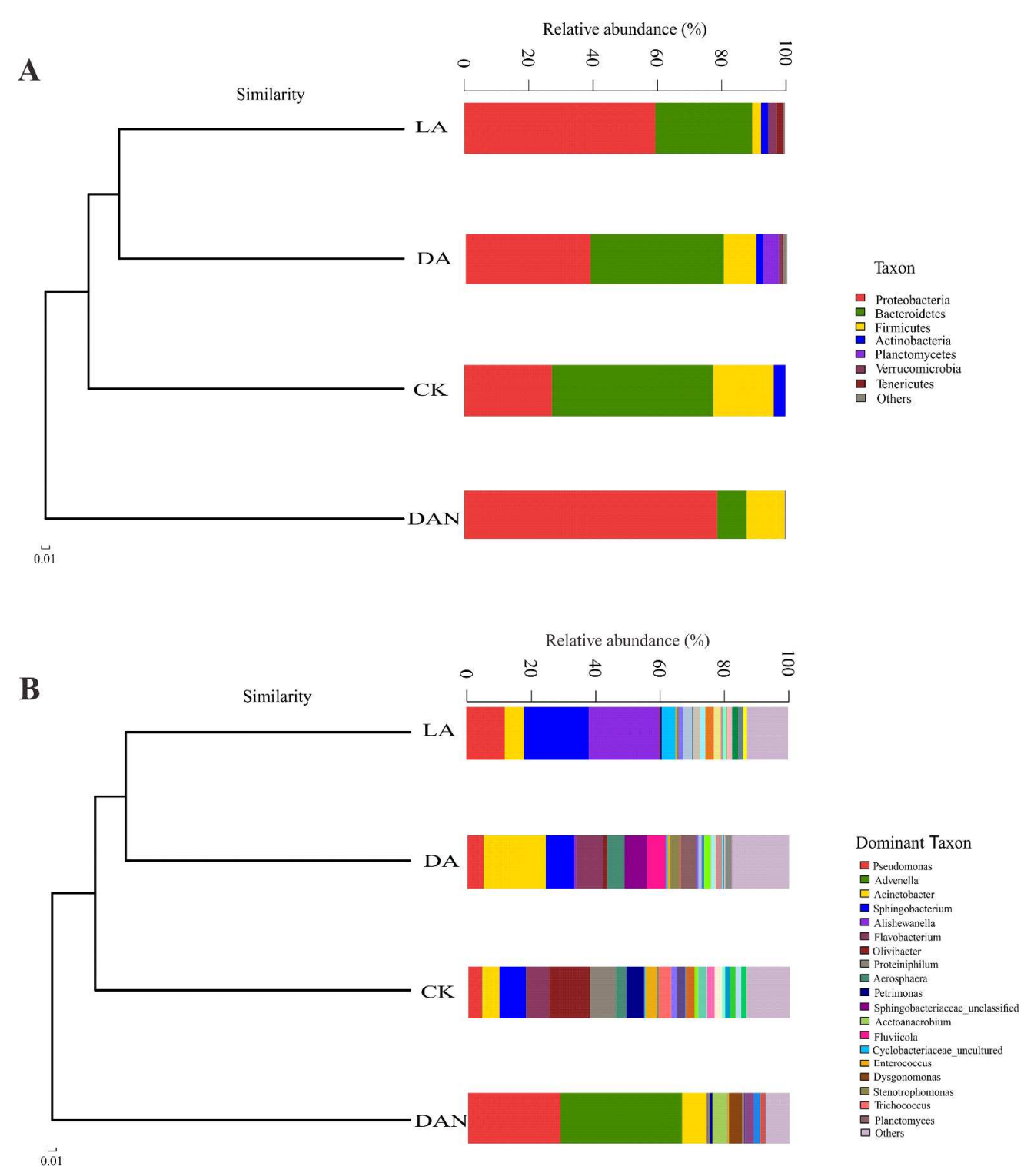

Figure 3 Relative abundances of bacterial taxa recovered from each sample with cluster tree. Figure $3 \mathrm{~A}$ shows the relative abundance of phyla. Figure 3B shows the relative abundance of genera 
A
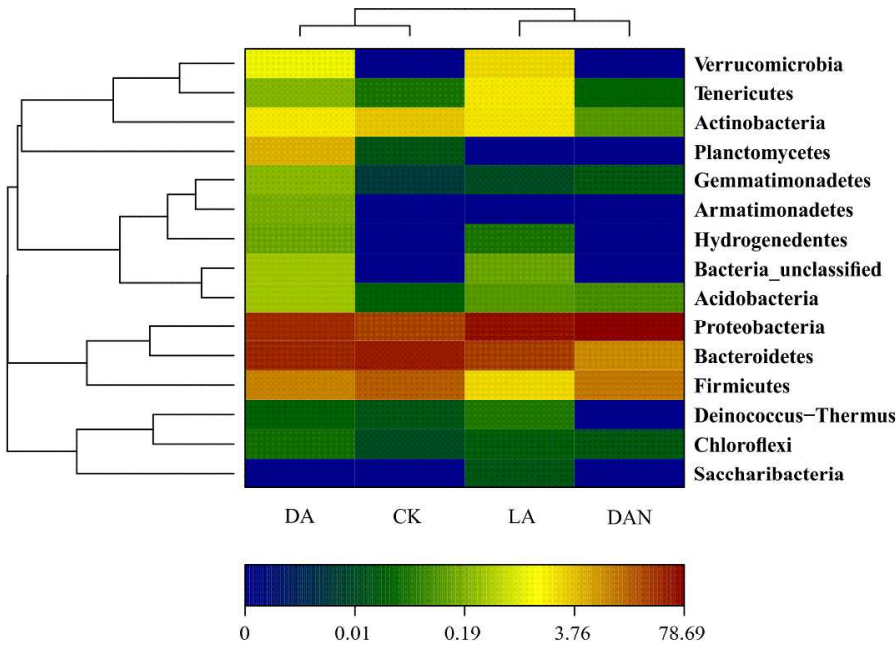

Relative abundance of community (\%)

B
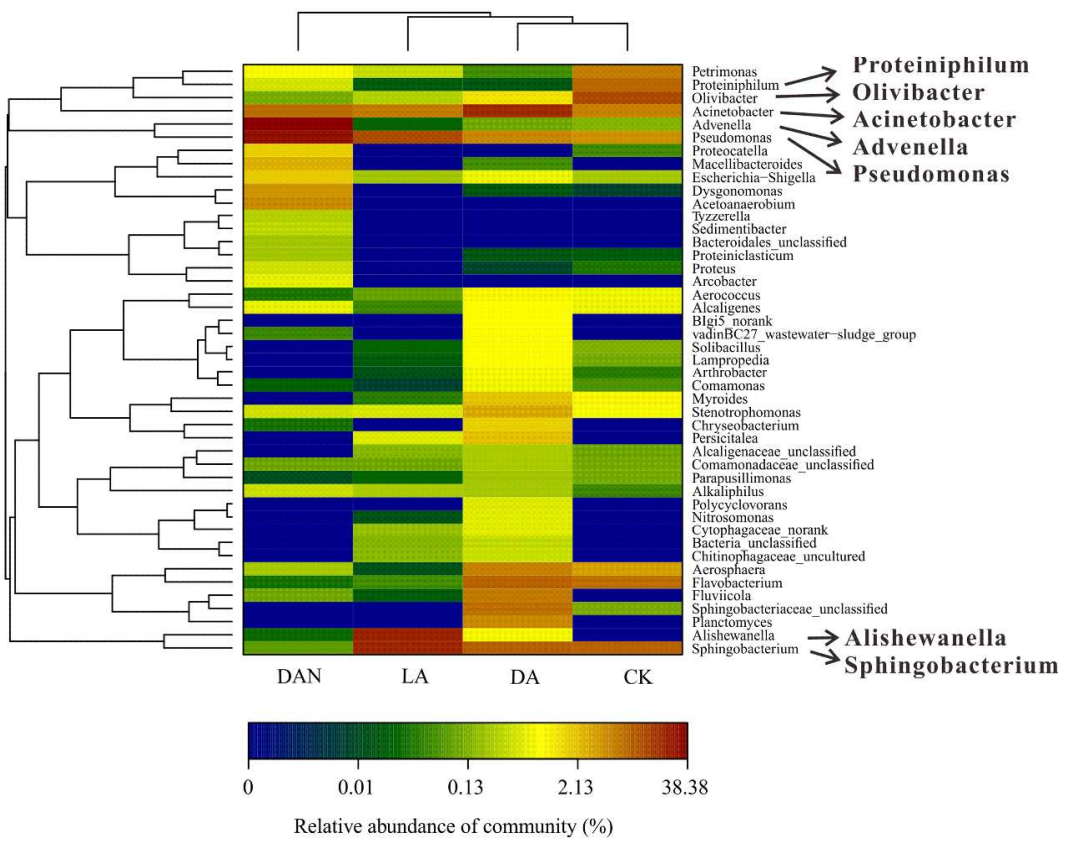

Figure 4 Heat map of bacterial taxa. A more red color indicates higher relative abundance. Figure $4 \mathrm{~A}$ shows the bacteria-phylum level distribution and Figure 4B shows bacteria-genus level distribution 